\title{
Marketing Strategy of Oyster Mushroom (Pleurotus Ostreatus) in Maritengngae District, Sidenreng Rappang Regency (Case Study of Independent Mushroom Business)
}

\author{
Dian Putri $^{1}$, Nurhapsa $^{2}$, A. Erna Sriwahyuningsih ${ }^{3}$ \\ ${ }^{123}$ PROGRAM STUDI AGRIBISNIS / FAKULTAS PERTANIAN, PETERNAKAN DAN \\ PERIKANAN / UNIVERSITAS MUHAMMADIYAH PAREPARE \\ Email : \\ putri.sumardi110@gmail.com ${ }^{1}$,Hapsa_faktan@yahoo.co.id ${ }^{2}$, Asyamshadiq@gmail.com ${ }^{3}$
}

(Received: Agu/2021; Reviewed: Sept/2021; Accepted: Sept/2021; Published: Okt/2021)

\begin{abstract}
The purpose of this study was to determine the internal (strengths and weaknesses) and external (opportunities and threats) factors in Mandiri Mushroom's business and to determine the right strategy for marketing oyster mushrooms in Mandiri Mushroom business. The analysis method used is the SWOT analysis. The result showed that internal and external factors based on weighting and rating obtained scores for the main strength factor in this Mandiri Mushrooms business werw the good quality of oyster mushrooms and the weakness namely the lack of venture capital. Meanwhile, the most supportive opportunity factor for marketing in this business is that it can compete with other oyster mushroom businesses and the threat factor that will be faced is the presence of pests that cause oyster mushrooms to not develop properly. The strategy that should be applied to this Mandiri Mushroom business based on the SWOT matrix is the StrengthsOpportunities ( $\mathrm{S}-\mathrm{O})$ strategy, which is to try to use its main strengths to maintain the quality of oyster mushrooms so that they get the main opportunity, which is to compete with other oyster mushrooms businesses.
\end{abstract}

Keywords: marketing strategy; SWOT Analysis; oyster mushrooms; EFAS; IFAS.

\section{ABSTRAK}

Tujuan dari penelitian ini adalah untuk mengetahui faktor-faktor internal (kekuatan dan kelemahan) dan eksternal (peluang dan ancaman) dalam usaha mandiri mushroom serta untuk menentukan strategi yang tepat untuk pemasaran jamur tiram di usaha mandiri mushroom. Adapun metode analisis yang digunakan adalah analisis SWOT. Dari hasil penelitian menunjukkan bahwa faktor internal dan eksternal berdasarkan pembobotan dan pemberian rating diperoleh skor untuk faktor kekuatan utama di usaha mandiri mushroom ini adalah kualitas jamur tiram yang baik dan kelemahannya yaitu kurangnya modal usaha. Sedangkan untuk faktor peluang paling mendukung pada pemasaran di usaha ini adalah dapat 
Dian Putri, Nurhapsa, A.Erna Sriwahyuningsih, 2021, Strategi Pemasaran Jamur Tiram (Pleurotus Ostreatus) Di Kecamatan Maritengngae Kabupaten Sidenreng Rappang (Studi Kasus Usaha Mandiri Mushroom)

bersaing dengan usaha jamur tiram yang lainnya dan faktor ancaman yang akan dihadapi adalah adanya hama yang menyebabkan jamur tiram tidak bisa berkembang dengan baik. Strategi yang sebaiknya diterapkan pada usaha Mandiri Mushroom ini berdasarkan Matriks SWOT adalah strategi Strenghts-Opportunities (S-O) yaitu berupaya menggunakan kekuatan utamanya mempertahankan kualitas jamur tiram sehingga memperoleh peluang utamanya yaitu dapat bersaing dengan usaha jamur tiram yang lain.

Kata Kunci: strategi pemasaran; analisis SWOT; jamur tiram; EFAS; IFAS

\section{PENDAHULUAN}

Masalah sosial ekonomi sangat dipengaruhi oleh minimnya lapangan kerja yang ada di masyarakat serta tingkat pendapatan rendah. Hal tersebut membuat tingginya motivasi masyarakat untuk menggali serta memanfaatkan sumber daya alam demi meningkatkan taraf hidup masyarakat (Nyompa et al., 2020). Salah satu upaya pemerintah untuk meningkatkan kontribusi pada sektor pertanian adalah pengembangan dari berbagai sektor diversifikasi produk pertanian. Mengingat bahwa pengembangan dalam sektor pertanian merupakan yang paling tangguh untuk menghadapi segala macam perubahan yang akan terjadi di Indonesia. Menurut (Nurdin et al., 2021) bahwa sektor pertanian memiliki peranan yang sangat penting di dalam suatu pembangunan nasional, selain itu sektor pertanian juga dikategorikan sebagai penopang perekonomian bangsa. Kondisi masyarakat yang tidak seluruhnya memiliki keterampilan, membuat mereka lebih memilih memanfaatkan sumber daya yang ada sebagai mata pencaharian pokok (Saputro et al., 2019).

Wilayah Indonesia merupakan salah satu negera yang memiliki minat pertanian diatas rata-rata. Menurut (Samat et al., 2021) bahwa wilayah pulau Sulawesi khusuwa di daerah Sulawesi Selatan merupakan provinsi yang sangat subur dan kaya akan hasil bumi seperti buah-buahan maupun sayur-mayur. Permintaan konsumen terhadap komoditas jamur tiram yang cukup besar membuat peluang bisnis jamur tiram yang bagus untuk dikembangkan sehingga mampu meningkatkan pendapatan petani dan kesejahteraan mereka. Bisnis jamur saat ini dan pada masa mendatang masih merupakan bisnis yang memiliki prospek yang sangat bagus, hal ini dikarenakan permintaan pasar belum bisa dipenuhi oleh produsen. Sementara penduduk Indonesia menurut data Badan pusat Statistik (BPS) tahun 2019, tingkat konsumsi jamur tiram sebesar 0,18 kg perkapita per tahunnya. Pada tahun 2018 tingkat konsumsi jamur tiram di Indonesia diperkirakan mencapai sekitar 3.442 ton dengan tingkat konsumsi mencapai $0,18 \mathrm{~kg}$ perkapita per tahun. Ini merupakan peluang untuk meningkatkan produksi jamur di Indonesia.

Tabel 1. Data Permintaan Dan Penawaran Jamur Tiram Di Sulawesi-Selatan

\begin{tabular}{lcc}
\hline \multicolumn{1}{c}{ Kabupaten/kota } & Permintaan (kg/bulan) & Penawaran (kg/bulan) \\
\hline Kab. Barru & 150 & 53 \\
Kota Parepare & 150 & 50 \\
Kab. Sidrap & 210 & 70
\end{tabular}




$\begin{array}{lll}\text { Kab. Pinrang } & 180 & 65 \\ \text { Kab. Maros } & 250 & 80 \\ \text { Kota Makassar } & 285 & 95 \\ \text { Kab. Gowa } & 200 & 80\end{array}$

Sumber : Badan Pusat Statistik Sulawesi Selatan 2019

Mandiri Mushroom merupakan salah satu usaha yang bergerak dibidang pembudidayaan jamur tiram. Usaha ini berlokasi di Jalan Melati, Kelurahan Majelling Wattang, Kecamatan Maritengngae, Kabupaten Sidenreng Rappang. Usaha ini didirikan oleh Novandi salah satu alumni dari jurusan Administrasi Publik, Sekolah Tinggi Ilmu Sosial dan Ilmu Politik Muhammadiyah Rappang. Kualitas jamur tiram yang ada di usaha ini termasuk kualitas yang baik yang ditandai dengan baglog yang sepenuhnya berwarna putih yang artinya baglog tersebut sudah ditumbuhi miselium-miselium jamur sehingga jamur tiram pada usaha ini dapat berkembang dengan baik. Dalam setiap bulannya usaha mandiri mushroom ini mampu memperoleh omset sekitar 1,5 juta dengan jumlah baglog 1000-1500 buah. Namun, terdapat permasalahan yang pada di usaha jamur tiram ini yakni : permintaan pasar yang belum bisa dipenuhi dan kapasitas produksi yang masih belum mampu memenuhi permintaan yang disebabkan oleh kurangnya modal dan pengetahuan yang dimiliki oleh petani. Sehingga usaha jamur tiram ini harus memiliki langkah yang strategis untuk mengembangkan usaha ini dalam menghadapi masalah untuk meraih peluang dalam mencapai tujuan dari usaha tersebut.

Permasalahan ini juga di alami oleh kelompok tani "aneka jamur" desa Gondangmanis berdasarkan penelitian yang dilakukan oleh (Retnaningsih \& C, 2018), dengan permasalahan produksi jamur yang masih belum mampu memenuhi permintaan konsumen di sebabkan oleh berbagai permasalahan yang ada. Dari hasil penelitian ini menyimpulkan menyimpulkan alternatif strategi yang diperoleh yaitu mempertahankan dan meningkatkan kualitas produk bibit dan baglog serta jamur tiramnya; meningkatkan kualitas SDM anggota kelompok dalam penanganan pasca panen; membentuk kemitraan dengan kelompok lain atau asosiasi dengan pembuat baglog atau pembudidayaan jamur sehingga tercapai kesepakatan harga; kerja sama dengan kelompok lain dalam keserempakan waktu untuk membuat baglog dan budidaya jamur sehingga apabila ada hama atau penyakit seluruh pembuat baglog atau pembudidaya jamur tiram tidak terserang semua; peningkatan efisiensi produksi untuk meningkatkan daya saing; dan penghematan melalui efisiensi biaya. Kesimpulan kedua yaitu prioritas strategi yang dapat dikembangkan untuk Kelompok Tani Aneka Jamur adalah mempertahankan dan meningkatkan kualitas produk bibit (F1) dan baglog (media tanam) serta jamur tiram.

Kemudian penelitian (Arminsyurita, 2018) menyimpulkan bahwa hasil analisis matriks diagram SWOT dan diagram IE maka dapat rekomendasikan strategi pemasaran perusahaan Rimba Jaya Mushroom antara lain dengan merebut pangsa pasar untuk penetrasi pasar dengan harga yang kompetitif, konsentrasi melalui integrasi ke belakang dengan menjalin hubungan dengan pemasok, konsentrasi melalui integrasi ke depan dengan cara mengambil alih fungsi distribusi secara keseluruhan, konsentrasi melalui integrasi horizontal dengan upaya kerja sama menggarap pasar terus membina hubungan dengan beberapa perusahaan sejenis atau mungkin mengadakan joint venture.

Penelitian serupa yang dilakukan oleh (Budasih et al., 2014), dengan jumlah sampel 12 orang menyimpulkan hasil perumusan strategi pemasaran berdasarkan Matriks IE, KWT Spora 
Bali berada pada kelompok usaha hold and maintain strategy (strategi mempertahankan dan memelihara), sehingga strategi yang dapat dilakukan adalah penetrasi pasar dengan cara meningkatkan penjualan atas produk dan pasar yang telah tersedia melalui usaha -usaha pemasaran yang lebih agresif seperti melakukan promosi secara langsung dan melalui media sosial. Dengan demikian diperoleh enam strategi aplikatif dari strategi penetrasi pasar yang merupakan hasil dari Matriks SWOT. Menurut (Arifah, 2011) bahwa strategi yang dapat dilakukan untuk pengembangan industri kecil jamur tiram di Kecamatan Jambu adalah dengan strategi konsentrasi melalui integrasi horizontal. Artinya strategi yang diterapkan lebih defensif, yaitu menghindari kehilangan penjualan dan kehilangan pendapatan.

Berdasarkan dari uraian yang telah dijelaskan di atas, penulis tertarik untuk melakukan penelitian dengan judul "Strategi Pemasaran jamur tiram (Pleurotus Ostreatus) di Kecamatan Maritengngae Kabupaten Sidrap (Studi Kasus pada Usaha Mandiri Mushroom)". Tujuan dari penelitian ini adalah untuk mengetahui faktor internal dan eksternal pada usaha mandiri mushroom dan menentukan strategi yang tepat yang sebaiknya digunakan untuk pemasaran jamur tiram di usaha tersebut.

\section{METODE}

Penelitian ini merupakan penelitian mix methods, yaitu suatu langkah penelitian yang menggabungkan dua jenis penelitian yakni penelitian kualitatif dan penelitian kuantitatif. Jenis penelitian ini adalah penelitian studi kasus yang merupakan kajian yang mendalam tentang peristiwa, lingkungan, dan situasi tertentu yang memungkinkan mengungkapkan atau memahami sesuatu hal. Penulis menggunakan bentuk penelitian studi kasus karena mengangkat fenomena yang terjadi di MANDIRI MUSHROOM tentang bagaimana strategi pemasaran jamur tiram.

Penelitian ini dilaksanakan di Kecamatan Maritenggae Kabupaten Sidenreng Rappang (SIDRAP) tepatnya di Mandiri Mushroom pada bulan September sampai Oktober 2020. Pemilihan lokasi didasarkan pada pertimbangan bahwa di Kabupaten Sidrap ini hanya terdapat satu-satunya petani jamur yang melakukan budidaya jamur tiram yaitu usaha Mandiri Mushroom. Populasi dalam penelitian ini adalah semua karyawan yang ada di Mandiri Musrhoom yang terdiri dari 5 orang, 2 orang pakar akademik dan 1 orang tenaga ahli, dimana semua populasi diambil sebagai sampel (sampel jenuh). Populasi merupakan wilayah umum dari objek atau subjek dengan kualitas dan karakteristik tertentu yang ditetapkan oleh peneliti untuk dipelajari kemudian disimpulkan (Santoso \& Tjiptono, 2001). Menurut (Sugiyono, 2009) sampling jenuh adalah teknik penentuan sampel bila semua anggota populasi digunakan sebagai sampel. Jadi, sampel yang ada dalam penelitian ini berjumlah 8 orang. 
Adapun teknik pengumpulan data yang digunakan penulis dalam penelitian ini adalah: Observasi, Wawancara, Kepustakaan, Dokumentasi dan Kuisioner. Data terkumpul dari hasil pengumpulan data, selanjutnya akan dilakukan analisis data yaitu proses mencari dan menyusun sistematis data yang diperoleh dari hasil wawancara dan observasi dengan cara mengorganisasikannya ke dalam kategori, menjabarkan ke dalam unit-unit, menyusun ke dalam suatu pola, memilih mana yang penting dan yang akan dipelajari dan membuat kesimpulan agar mudah dipahami oleh diri sendiri maupun orang lain.

Data-data yang diperoleh dalam penelitian ini kemudian dianalisis dan diolah secara kualitatif dan kuantitatif, Selanjutnya data-data dikumpulkan menggunakan matriks IFAS dan matriks EFAS, hal ini dilakukan untuk mengembangkan faktor kelebihan dan peluang yang kiranya dapat dimanfaatkan serta faktor kelemahan dan ancaman yang perlu dihindari. Hasil analisis eksternal dilanjutkan dengan mengevaluasi guna mengetahui apakah strategi yang dipakai selama ini memberikan respon terhadap faktor-faktor yang ada. Sedangkan untuk menganalisis masalah selanjutnya digunakan matriks SWOT yang kemudian akan menghasilkan alternatif strategi yang sebaiknya di terapkan. Hasil pengolahan data disajikan dalam bentuk tabel, gambar dan uraian.

Definisi Operasional

1. Strategi adalah gagasan atau perencanaan yang dirancang untuk memastikan suatu tujuan yang ingin di capai dapat terlaksana dengan tepat dan benar.

2. Analisis SWOT merupakan identifikasi berbagai faktor untuk merumuskan suatu strategi yang akan di gunakan. SWOT terdiri dari Kekuatan (Strenghts), Kelemahan (Weeknesses), Peluang (Oppourtunities) dan Ancaman (Threats)

3. IFAS (Interal Strategic Factors Analysis Summary) adalah ringkasan atau rumusan faktorfaktor strategi internal dalam bagian kerangka Kekuatan (Strenghts) dan kelemahan (Weeknesses).

4. EFAS (Interal Strategic Factors Analysis Summary) adalah ringkasan atau rumusan faktor strategi eksternal dalam bagian kerangka Peluang (Oppourtunities) dan Ancaman (Threats).

5. Matriks SWOT yaitu cara menentukan startegi yang dapat digunakan, dan dapat menggambarkan secara jelas bagaimana pelung dan ancaman yang di hadapi, dan disesuaikan dengan kekutan dan kelematan yang dimiliki.

\section{HASIL DAN PEMBAHASAN}

\section{Hasil}

Penilaian faktor eksternal dan internal dengan pemberian bobot dan rating terhadap masing-masing faktor yang di isi dalam kuisioner dilakukan oleh 8 orang responden antara lain 1 orang pemilik usaha, 4 orang karyawan, 1 orang tenaga ahli yakni Dari Dinas Tanaman Pangan, Hortikultira, Perkebunan Dan Ketahanan Pangan Kabupaten Sidrap dan 2 orang pakar akademik yakni Dosen Fakultas Pertanian, Peternakan Dan Perikanan Universitas Muhammadiyah Parepare.

\section{Hasil Evaluasi Faktor Internal (IFAS)}


Dian Putri, Nurhapsa, A.Erna Sriwahyuningsih, 2021, Strategi Pemasaran Jamur Tiram

(Pleurotus Ostreatus) Di Kecamatan Maritengngae Kabupaten Sidenreng Rappang

(Studi Kasus Usaha Mandiri Mushroom)

Evaluasi faktor internal diperoleh dari nilai bobot dan rating sesuai dengan pendapat responden. Faktor kekuatan dan kelemahan dapat dilihat dari tabel berikut.

Tabel 1. Hasil Evaluasi Faktor Internal (Kekuatan)

\begin{tabular}{clccc}
\hline \multicolumn{5}{c}{ Faktor-Faktor Internal } \\
\hline No & \multicolumn{1}{c}{ Kekuatan (S) } & Bobot & Rating & Skor \\
\hline 1 & Harga jamur yang terjangkau. & 0,20 & 3 & 0,60 \\
2 & Tersedianya bahan baku. & 0,22 & 4 & 0,88 \\
3 & Kualitas jamur tiram yang baik. & 0,23 & 4 & 0,92 \\
4 & Jamur tiram dapat dipanen setiap hari. & 0,16 & 3 & 0,48 \\
5 & Semakin banyaknya produk olahan jamur tiram & 0,18 & 3 & 0,54 \\
\hline \multicolumn{2}{c}{ Sub Total } & $\mathbf{0 , 9 9}$ & & $\mathbf{3 , 4 2}$ \\
\hline
\end{tabular}

Sumber : data primer setelah diolah, (2020).

Tabel 2. Hasil Evaluasi Faktor Internal (Kelemahan)

\begin{tabular}{clccc}
\hline \multicolumn{5}{c}{ Faktor-Faktor Internal } \\
\hline No & \multicolumn{1}{c}{ Kelemahan (W) } & Bobot & Rating & Skor \\
\hline 1 & Modal usaha masih kurang & 0,22 & 1 & 0,22 \\
2 & Wilayah distribusi masih kurang & 0,21 & 1 & 0,21 \\
3 & Jamur tiram tidak tahan lama & 0,17 & 2 & 0,34 \\
4 & Permintaan pasar belum bisa terpenuhi & 0,23 & 2 & 0,46 \\
5 & Belum memiliki label atau merek & 0,15 & 3 & 0,45 \\
\hline \multicolumn{5}{c}{ Sub Total } \\
\hline
\end{tabular}

Sumber : data primer setelah diolah, (2020).

\section{Hasil Evaluasi Faktor Eksternal (EFAS)}

Hasil evaluasi faktor eksternal diperoleh nilai bobot dan rating dari pendapat informan kunci (ekspert) masing-masing faktor peluang dan ancaman dapat dilihat pada tabel berikut.

Tabel 3. Hasil Evaluasi Faktor Eksternal (Peluang)

\begin{tabular}{clccc}
\hline \multicolumn{5}{c}{ Faktor-Faktor Eksternal } \\
\hline No & \multicolumn{1}{c}{ Peluang (O) } & Bobot & Rating & Skor \\
\hline 1 & $\begin{array}{l}\text { Dapat bersaing dengan usaha jamur tiram } \\
\text { yang lain. }\end{array}$ & 0,20 & 4 & 0,80 \\
2 & $\begin{array}{l}\text { Dukungan dari pemerintah. } \\
\text { Semakin meningkatnya selera masyarakat }\end{array}$ & 0,21 & 2 & 0,42 \\
$\begin{array}{l}\text { untuk mengkonsumsi jamur tiram. } \\
\text { Daya beli masyarakat yang besar terhadap } \\
\text { jamur tiram. }\end{array}$ & 0,20 & 3 & 0,54 \\
$\begin{array}{l}\text { Tingganya inovasi produk olahan jamur } \\
\text { tiram }\end{array}$ & 0,20 & 3 & 0,60 \\
\hline & Sub Total & $\mathbf{0 , 9 9}$ & & $\mathbf{2 , 9 6}$ \\
\hline
\end{tabular}

Sumber : data primer setelah diolah, (2020). 
Dian Putri, Nurhapsa, A.Erna Sriwahyuningsih, 2021, Strategi Pemasaran Jamur Tiram

(Pleurotus Ostreatus) Di Kecamatan Maritengngae Kabupaten Sidenreng Rappang (Studi Kasus Usaha Mandiri Mushroom)

Tabel 4. Hasil Evaluasi Faktor Eksternal (Ancaman)

\section{Faktor-Faktor Eksternal}

\begin{tabular}{clccc}
\hline No & \multicolumn{1}{c}{ Ancaman (T) } & Bobot & Rating & Skor \\
\hline 1 & Persaingan dengan usaha yang sejenis. & 0,22 & 3 & 0,66 \\
2 & Perkembangan teknologi. & 0,16 & 3 & 0,48 \\
3 & Sering terjadi perubahan cuaca. & 0,20 & 2 & 0,40 \\
4 & Daya tarik inovasi olahan jamur tiram lainnya. & 0,15 & 3 & 0,45 \\
5 & Adanya hama yang menyebabkan jamur tiram & 0,26 & 1 & 0,26 \\
\hline & $\quad$ tidak bisa berkembang dengan baik. & $\mathbf{0 , 9 9}$ & & $\mathbf{2 , 2 5}$
\end{tabular}

Sumber : data primer setelah diolah, (2020).

\section{Matriks Grand Strategi}

Data yang diperoleh setelah melakukan penelitian di Kecamatan Maritengngae Kabupaten Sidrap Tepatnya di Usaha Mandiri Mushroom maka diperoleh nilai sumbu X berasal dari selisih faktor internal (faktor kekuatan dan kelemahan) pada usaha, dan nilai sumbu Y berasal dari selisih faktor eksternal (faktor ancaman dan peluang) pada usaha tersebut.

Dapat dilihat pada gambar.

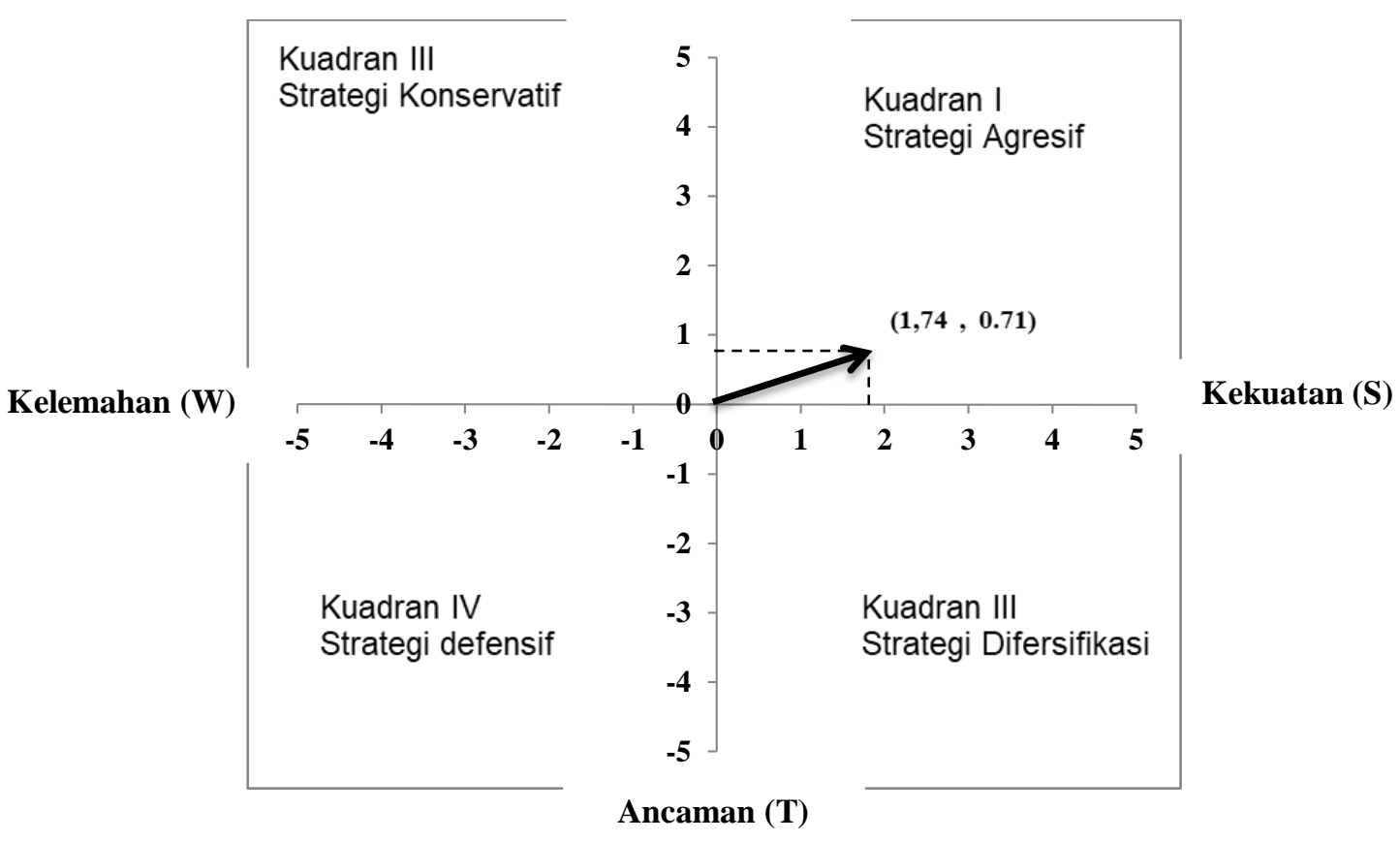

Gambar 3. Diagram Matriks Grand strategy

\section{Pembahasan}




\section{Faktor Internal Pada Usaha Mandiri Mushroom.}

Faktor lingkungan internal terdiri dari faktor kekuatan yang terdapat dan faktor kelemahan yang dialami usaha mandiri mushroom ini. Adapun faktor-faktor internal tersebut antara lain sebagai berikut : (1). Kualitas jamur tiram yang baik, (2). Tersedianya bahan baku, (3). Harga jamur tiram yang terjangkau, (4). Semakin banyak produk olahan jamur tiram, (5). Jamur tiram dapat dipanen setiap hari, (6). Modal usaha yang masih kurang, (7). Wilayah distribusi masih kurang, (8). Permintaan pasar belum bisa terpenuhi, (9). Jamur tiram tidak tahan lama. (10). Belum memiliki label atau merek. Dengan kekuatan utamanya yaitu kualitas jamur tiram yang tinggi sehinggi menjadi modal untuk pemasaran jamur tiram tersebut. Menurut hermawan, jamur tiram yang dihasilkan harus berkualitas baik kerena berkaitan dengan bauran pemasaran tentang produk. Menjaga dan meningkatkan kualitas produk dengan baik dengan tidak menggunakan bahan-bahan kimia dalam melakukan proses produksi, baik untuk melakukan pemupukan maupun mengatasi hama penyakit. Hal itu dilakukan untuk menjaga agar produk yang dihasilkan aman untuk konsumen, sedangkan kelemahan dari usaha ini adalah wilayah distribusi yang masih kurang disebabkan karena kurangnya promosi dan sosialisasi yang dilakukan dalam memasarkan jamur tiramnya.

\section{Faktor Ekternal Pada Usaha Mandiri Mushroom.}

Faktor lingkungan eksternal terdiri dari faktor peluang yang dimanfaatkan dan faktor ancaman yang akan dihadapi usaha mandiri mushroom ini. Adapun faktor-faktor eksternal tersebut antara lain sebagai berikut : (1). Dapat bersaing dengan usaha jamur tiram yang lain, (2). Dukungan dari pemerintah, (3). Semakin meningkatnya selera masyarakat untuk mengkonsumsi jamur tiram, (4). Daya beli masyarakat yang besar terhadap jamur tiram, (5). Tingginya inovasi produk olahan jamur tiram, (6). Persaingan dengan usaha yang sejenis, (7). Perkembangan teknologi, (8). Sering terjadi perubahan cuaca, (9). Daya tarik inovasi olahan jamur tiram lainnya, (10). Adanya hama yang menyebabkan jamur tiram tidak bisa berkembang dengan baik. Adapun peluang yang paling mempengaruhi usaha ini adalah adanya dukungan dari pemerintah. Sedangkan ancaman utama yang akan dihadapi adalah terdapat hama yang dapat menyebabkan jamur tiram tidak bisa berkembang dengan baik, ini merupakan ancama utama yang di alami usaha ini karena dapat menurunkan nilai jual jamur tiram dan merusak kualitas jamur tiram sehingga dapat merugikan pelaku usaha mandiri mushrom tersebut. Menurut (Sumarlan \& Fauzia, 2016) suhu dan kelembaban media tanam jamur yang tidak sesuai menyebabkan munculnya hama ataupun penyakit pada jamur yang menyebabkan jamur tidak bisa berkembang dengan baik.

\section{Strategi Pemasaran Jamur Tiram}

Dengan melihat nilai dari analisis IFAS dan EFAS maka dapat dihitung bahwa nilai skor kekuatan ditambah dengan nilai skor kelemahan dan nilai skor peluang ditambah dengan ancaman. Berdasarkan hal tersebut maka nilai strength (kekuatan) ditambah dengan Weakness 
(kelemahan), 3,42 + (-3,22) hasilnya 0,2 dan nilai opportunity (peluang) ditambah dengan Treath (ancaman), 2,96+(-2,70) dan hasilnya 0,26.

Pada gambar 1 menunjukkan bahwa pemasaran jamur tiram di Kecamatan Maritengngae Kabupaten Sidrap (Studi Kasus di usaha mandiri mushroom) berada pada kuadran I berarti mendukung strategi agresif dimana jamur tiram pada usaha ini memiliki peluang yang besar dalam memasarkannya karena hanya ada satu usaha yang bertahan dan masih membudidayakan jamur tiram Dikecamatan Maritengngae, sehingga dapat memanfaatkan peluang yang ada dengan memaksimalkan kekuatan yang dimiliki yakni kualitas jamur tiram yang baik dan bahan baku mudah untuk didapatkan.

Kuadran I merupakan situasi yang sangat menguntungkan. Perusahaan tersebut memiliki peluang dan kekuatan sehingga peluang yang ada dapat dimanfaatkan dengan baik. Strategi yang harus diterapkan dalam kondisi ini adalah mendukung kebijakan pertumbuhan yang agresif (Growth oriented strategi) (Freddy, 2006)

Hasil dari penelitian ini sejalan dengan penelitian (Retnaningsih \& C, 2018) yang menyimpulkan prioritas strategi yang dapat dikembangkan untuk Kelompok Tani Aneka Jamur adalah mempertahankan dan kualitas produk bibit (F1) dan baglog (media tanam) serta jamur tiram. Sedangkan menurut (Lubis, 2019) dengan judul "Analisis Strategi Pengembangan Usaha Arang di Desa Paya Pasir, Kecamatan Tebing Syahbadar, Kabupaten Serdang Berdagai” strategi S-O Terdiri dari produk berkualitas dan permintaan produk semakin dapat dimanfaatkan untuk memasarkan produk secara lebih luas karena produk yang dihasilkan berkualitas maka permintaan produk akan semakin meningkat/tinggi, ini merupakan hal yang baik untuk melakukan strategi pemasaran.

Strategi Pemasaran Jamur Tiram (Pleurotus Ostreatus) Di Kecamatan Maritengngae Kabupaten Sidrap (Studi Kasus Pada Usaha Mandiri Mushroom) yang tepat adalah sebagai berikut :

\section{Strategi Strenghts-Opportunities (S-O)}

Strategi S-O adalah strategi yang memanfaatkan untuk meraih peluang yang ada pada lingkungan eksternal guna memperoleh keuntungan dalam mencapai tujuan perusahaan. Terdapat alternatif strategi S-O yang sebaiknya diterapkan di Usaha Mandiri Mushroom yaitu :

a. Memaksimalkan kualitas jamur tiram sehingga daya beli masyarakat terhadap jamur tiram juga tinggi dan juga dapat bersaing dengan usaha jamur tiram yang lainnya.

b. Memaksimalkan bahan baku yang tersedia dengan menambah jumlah produksi jamur tiram.

\section{Strategi Weakness-Opportunities (W-O)}

Strategi W-O merupakan penggabungan antar faktor kelemahan dan peluang yang bertujuan untuk meminimalakan kelemahan untuk memanfaatkan peluang yang ada. Terdapat alternatif strategi W-O yang sebaiknya diterapkan di Usaha Mandiri Mushroom yaitu : 
a. Memaksimalkan inovasi produk olahan jamur tiram agar memiliki nilai tambah lebih dan meminimalkan jamur tiram yang tidak tahan lama.

b. Meningkatkan wilayah distribusi dengan melakukan promosi dengan cara mempromoskan jamur tiram di usaha mandiri mushroom melalui media sosial.

\section{Strategi Strengths-Threats (S-T)}

Strategi S-T merupakan penggabungan antara faktor kekuatan dengan faktor ancaman dengan cara menggunakan kekuatan untuk mengatasi ancaman yang akan dihadapi oleh perusahaan. Terdapat alternatif strategi S-T yang sebaiknya digunakan di Usaha Mandiri Mushroom yaitu :

a. Memaksimalkan kualitas jamur tiram dalam menghadapi akan banyaknya usaha yang sejenis.

b. Meningkatkan jenis produk olahan jamur tiram sehingga masyarakat/konsumen dapat menjadikannya alternatif lain untuk mengkonsumsi jamur tiram.

\section{Strategi Weakness-Threats (W-T)}

Strategi W-T merupakan penggabungan antara faktor kelemahan dan ancaman yang bertujuan untuk meminimalkan kelemahan untuk menghindari ancaman. Terdapat alternatif strategi W-T yang sebaiknya digunakan di Usaha Mandiri Mushroom yaitu :

a. Mengoptimalkan perawatan dan pemeliharaan jamur tiram untuk menghindari serangan hama yang dapat menghambat perkembangan jamur tiram.

b. Memanfaatkan perkembangan teknologi untuk memperoleh informasi tentang cara perawatan, penyimpanan dan pemasaran jamur .

\section{Simpulan}

\section{SIMPULAN DAN SARAN}

Hasil identifikasi faktor internal (kekuatan dan kelemahan) dan faktor internal (peluang dan ancaman) berdasarkan hasil pembobotan dan pemberian rating diperoleh skor, untuk faktor kekuatan utama di usaha mandiri mushroom ini adalah kualitas jamur tiram yang baik dan untuk faktor kelemahan utama yaitu kurangnya modal usaha. Sedangkan untuk faktor peluang yang paling mendukung pemasaran di usaha mandiri mushroom ini adalah dapat bersaing dengan usaha jamur tiram yang lainnya dan faktor ancaman utama yang akan dihadapi usaha ini adalah Adanya hama yang menyebabkan jamur tiram tidak bisa berkembang dengan baik.

Strategi pemasaran jamur tiram (pleurotus ostreartus) di kecamatan maritengngae kabupaten sidrap (studi kasus pada usaha mandiri mushroom) yang menjadi hasil penetapan strategi yang sebaiknya diterapakan dari hasil analisis SWOT berdasarkan matriks SWOT maka strategi yang tepat digunakan adalah strategi Strenghts-Opportunities (S-O) yaitu berupaya menggunakan kekuatan utamanya mempertahankan kualitas jamur tiram sehingga memperoleh peluang utamanya yaitu dapat bersaing dengan usaha jamur tiram yang lain. Hasil rekomendasi berdasarkan matriks SWOT yaitu Memaksimalkan kualitas jamur tiram agar mampu meningkatkan daya beli masyarakat terhadap jamur tiram. 


\section{Saran}

Peneliti menyarankan kepada pihak terbaik pada penelitian ini yaitu dukungan pemerintah sangat diperlukan dalam memberikan peluang bagi para pelaku di usaha mandiri mushroom khususnya modal usaha guna untuk meningkatkan kualitas dan kuantitas produk dan juga dari segi pemasaran produk, serta senantiasa mempertahankan kualitas jamur tiram yang baik.

\section{DAFTAR RUJUKAN}

Arifah. (2011). Jamur Tiram Di Kecamatan Jambu Kabupaten Semarang.

Arminsyurita, A. (2018). Analisis Strategi Pemasaran Jamur Rimba Jaya Mushroom. Transparansi Jurnal Ilmiah Ilmu Administrasi, 6(2), 156-168. https://doi.org/10.31334/trans.v6i2.39

Budasih, N., Ambarawati, I., \& Astiti, N. (2014). Strategi Pemasaran Produk Olahan Jamur Tiram pada Kelompok Wanita Tani (KWT) Spora Bali. Jurnal Manajemen Agribisnis, 2(2), 26282.

Freddy, R. (2006). Analisis SWOT teknik membedah kasus bisnis. PT Gramedia Pustaka Utama, Jakarta.

Lubis, A. S. L. (2019). Analisis Strategi Pengembangan Usaha Arang Di Desa Paya Pasir, Kecamatan Tebing Syahbandar, Kabupaten Serdang Bedagai.

Nurdin, R., Yusriadi, Y., \& Sriwahyuningsih, A. E. (2021). Pengaruh Penggunaan Alsintan Terhadap Pendapatan Petani (Studi Kasus di Kelompok Tani Barantas Kab. Sidenreng Rappang). LaGeografia, 19(3), 273-283.

Nyompa, S., Dewi, N. A. S., \& Sideng, U. (2020). Dampak Keberadaan Tambang Pasir Terhadap Kondisi Sosial Ekonomi Masyarakat di Desa Cimpu Utara Kecamatan Suli Kabupaten Luwu. LaGeografia, 18(2), 137-149.

Retnaningsih, N., \& C, B. N. (2018). STRATEGI PENGEMBANGAN JAMUR TIRAM (Pleurotus Ostreatus) DI KELOMPOK TANI ANEKA JAMUR DESA GONDANGMANIS KECAMATAN KARANGPANDAN KABUPATEN KARANGANYAR. SEPA: Jurnal Sosial Ekonomi Pertanian Dan Agribisnis, 14(1), 61. https://doi.org/10.20961/sepa.v14i1.21048

Samat, A., Invanni, I., \& Badwi, N. (2021). Profil Sosial Ekonomi Pedagang Durian di Desa Sabbang Kecamatan Sabbang Kabupaten Luwu Utara. LaGeografia, 19(3), 387-400.

Santoso, S., \& Tjiptono, F. (2001). Riset Pemasaran: konsep dan aplikasi dengan SPSS. PT. Elex Media Komputindo, Jakarta.

Saputro, A., Nyompa, S., \& Arfan, A. (2019). Analisis Pemanfaatan Hutan Mangrove dan Kontribusinya Terhadap Pendapatan Rumah Tangga Masyarakat di Pulau Tanakeke Kabupaten Takalar. LaGeografia, 18(1), 70-81.

Sugiyono, P. D. (2009). Metode Penelitian Kuantitatif Kualitatif Dan R\&D, Bandung: $C v$. Alvabeta.

Sumarlan, N. A. L., \& Fauzia, I. (2016). Strategi Pemasaran Jamur Tiram Putih (Pleurotus SP) di Kota Medan. Journal of Agriculture and Agribusiness Socioeconomics, 4(8), 94276. 